\title{
Early detection of unhealthy behaviors, the prevalence and receipt of antiviral treatment for disabled adult hepatitis B and $C$ carriers
}

\author{
Sui-Whi Jane ${ }^{1+}$, Ming-Shyan Lin ${ }^{2 \dagger}$, Wen-Nan Chiu ${ }^{2}$, Li-Ju Lai ${ }^{3}$, Po-Han Chen ${ }^{4}$ and Mei-Yen Chen ${ }^{5^{*}}$
}

\begin{abstract}
Background: Evidence indicates that hepatitis B virus (HBV) and hepatitis C virus (HCV) infections are the leading causes of liver cirrhosis and hepatocellular carcinoma. Antiviral treatments have recently been reported as successful cures. However, the prevalence rates of HBV or HCV infection, unhealthy behaviors and receipt of adequate treatment in disabled adults have not been described. The aim of this study was to examine the prevalence of HBV or HCV carriers, receipt of antiviral treatment, and early detection of unhealthy behaviors in disabled adults in Taiwan.
\end{abstract}

Methods: A population-based, cross-sectional study was conducted between July and December 2013 with 845 community-dwelling adults with disabilities aged $>20$ years. Statistical analyses included descriptive statistics, Chi-squared tests, and stepwise regression analysis.

Results: The prevalence of HBV and HCV infections was 12.9 and $14.1 \%$, respectively. HCV carriers tended to be older $(p<0.001)$ and with a lower education $(p<0.001)$. The majority of HBV/HCV carriers did not know the type of hepatitis infection and did not receive adequate antiviral treatment. After adjusting for potential confounding variables, regression analysis showed that the factors significantly associated with elevated liver function were HCV infection $(p<0.001)$, HBV infection $(p=0.001)$, high fasting blood glucose levels $(p=0.001)$, overweight $(p=0.003)$, older age $(p=0.027)$, and alcohol drinking $(p=0.028)$.

Conclusions: There was a high prevalence of HCV infection among adults with disabilities; few received adequate antiviral treatment or early detection of unhealthy behaviors for the prevention of liver cancer. Clinicians can provide health education to help the participants and caregivers better understand the relationships between specific risk factors and liver health and can encourage HBV and HCV carriers to undergo annual physical check-ups and receive adequate treatment, as covered by the national health insurance.

Keywords: Prevalence, Unhealthy behavior, Hepatitis B virus, Hepatitis C virus, Disability

\section{Background}

Liver cancer is one of the most common cancers worldwide, particularly in Central and East Asia [1]. The leading causes of liver cirrhosis, liver failure, and hepatocellular carcinoma (HCC) are hepatitis B virus (HBV) and hepatitis $\mathrm{C}$ virus $(\mathrm{HCV})$ infections. Hepatitis is inflammation

\footnotetext{
* Correspondence: meiyen@mail.cgust.edu.tw

${ }^{\dagger}$ Equal contributors

${ }^{5}$ College of Nursing, Chang Gung University of Science and Technology, No.

2, Chiapu Rd. West Sec., Putz City, Chiayi County 61363, Taiwan

Full list of author information is available at the end of the article
}

of the liver, most commonly caused by a viral infection [1-4]. The mechanism by which hepatitis viral infection leads to liver cancer might involve the infection-related chronic inflammation $[3,4]$.

Globally, HBV and HCV infections and their sequelae remain a major health problem, associated with 1.45 million deaths annually [5]. In Taiwan, liver cirrhosis and HCC are the most common causes of death, accounting for 34.9 deaths per 100,000 persons [6]. In addition, HBV and $\mathrm{HCV}$ are endemic, with prevalence rates of $15-20$ and $2-3 \%$, respectively, among the 
general adult population. An estimated 2.5-3.0 million people are HBV carriers, and nearly $90 \%$ of HCC patients are infected with HBV or HCV. Furthermore, $60-90 \%$ of carriers are at risk of liver cirrhosis and HCC $[6,7]$. In Taiwan, HCV infection is significantly associated with health disparity and older people in disadvantaged areas [8-10].

HBV infection occurs mainly during early childhood, and mother-to-infant transmission accounts for the majority of cases with chronic infection [3]. The majority of $\mathrm{HCV}$ infections are transmitted via contact with the blood of an infected person or with unsterilized materials, such as injectable drug equipment, razors, or tattoo needles [4]. Fortunately, Taiwan launched a universal HBV vaccination program in 1984, in which three HBV vaccine doses were administered to all infants starting from the first week of life [3]. Long-term studies have demonstrated that 20 years after the mass HBV vaccination program was implemented, the incidence of HBV infection significantly declined to $0.6 \%$ in young adults [11, 12]. Additionally, antiviral treatments for HBV and $\mathrm{HCV}$ in adult carriers, such as interferon combined with ribavirin, have recently been reported as successful cures [1-4]. However, many people still receive inadequate treatment, especially disabled residents living in rural areas [10].

In Taiwan, more than one million people were designated as disabled by the government in 2012 [13]. The top five disabilities were physical disability, loss of vital organs, hearing impairment, intellectual disability, and a combination of disabilities. People with disabilities have poorer health outcomes, less education, less economic participation, and higher rates of poverty than people without disabilities [14]. Therefore, disability has become a human rights issue in Taiwan; the potential health care savings due to early intervention and prevention efforts have also recently been recognized [13].

Liver dysfunction, such as abnormal serum glutamatepyruvate transaminase (SGPT) levels, and HCC have been associated not only with $\mathrm{HBV}$ or $\mathrm{HCV}$ infection but also with cigarette smoking, alcohol drinking, and obesity [10, 15-18]. In addition, obesity is an increasingly important health problem in disabled people [19]. Therefore, reductions in weight might reverse the burden of liver function; strategies for weight loss include adopting a healthier diet (e.g., 3 servings of vegetables and 2 servings of fruit daily), drinking plenty of water (e.g., $1500 \mathrm{~mL} /$ day), and exercising (e.g., $30 \mathrm{~min} /$ day, 3 times per week) [20].

Few actions have been implemented to enhance cancer prevention policies among HBV or HCV carriers in disadvantaged areas. Moreover, few studies have explored the prevalence of and relationships with unhealthy behaviors, health status, and receipt of adequate treatment among disabled HBV or HCV carriers. In this study, we investigated the prevalence of and relationships between unhealthy behaviors and determinants of liver function among disabled $\mathrm{HBV} / \mathrm{HCV}$ carriers.

\section{Methods}

\section{Participants and design}

This study was part of a health promotion program for community-dwelling adults with disabilities led by a nursing team in collaboration with a private hospital and the Bureau of Health Promotion in Chiayi County, Taiwan. This cross-sectional, descriptive study aimed to explore the prevalence of $\mathrm{HBV} / \mathrm{HCV}$ carriers and receipt of anti-viral treatment in the southwestern coastal area. In this area, there were 37,629 people with disabilities, based on government records [13]; from these records, participants were selected by convenience sampling. The inclusion criteria were the ability to (1) complete the questionnaire in writing or by interview in Mandarin or Taiwanese with or without assistance or via a caregiver, (2) walk or transfer to the local hospital with or without assistance from family or institutional staff, and (3) provide written informed consent before study enrollment. Participants who were unable to answer questions, who had severe chronic disease or cancer, or who were undergoing dialysis were excluded.

A community-based health screening survey was conducted between July and December 2013, and 1024 disabled residents participated in this project. From this information, we determined the prevalence rates of viral infections, receipt of adequate antiviral treatments, unhealthy behaviors, and risk factors associated with liver function among disabled $\mathrm{HBV} / \mathrm{HCV}$ carriers.

\section{Instruments and measurements}

A. Demographic characteristics included age, gender, education level (years of education achieved), marital status, occupation, living arrangement, and disability classification. Disabilities were classified according to the government definition (e.g., physical, intellectual, and multiple disabilities) and confirmed before the interview was conducted.

B. Unhealthy behaviors and receipt of anti-virus treatment were assessed based on expert recommendations related to adopting healthy lifestyles and habits for the liver $[10,20]$ using eight questions (1) "Do you regularly drink alcohol?" Drinking was classified as "never" if the participant had never consumed alcohol, "ceased" if the participant had previously consumed alcohol but had ceased drinking alcohol for at least 6 months, or "current" if the participant was currently drinking. (2) "Do you smoke cigarettes?" Smoking was classified as "never" 
if the participant never smoked, "ceased" if the participant had previously smoked but had ceased smoking for at least 6 months, or "current" if the participant was currently smoking. (3) Regular exercise was classified as "irregular" if the participant responded never or sometimes or as "regular" if the participant usually exercised for a total or cumulative duration of $>30$ min per day, three times per week, or 150 min per week. (4) "How often do you consume at least $1500 \mathrm{~mL}$ or eight bowl-sized cups of water each day?" The answer was classified as "insufficient" if the participant answered never or sometimes and as "sufficient" if the participant answered usually or always. (5) "Do you eat 3 servings of vegetables every day?" The answer was classified as "insufficient" if the participant answered never or sometimes and as "sufficient" if the participant usually consumed at least 3 servings or 1.5 bowl-sized servings of vegetables per day. (6) "Do you eat 2 servings of fruit every day?" The answer was classified as "insufficient" if the participant answered never or sometimes and as "sufficient" if the participant usually consumed at least 2 servings or one bowl-sized serving of fruit per day. (7) "Do you know that you have a viral infection called hepatitis?" If yes, then the participant was asked (8) "Have you received hepatitis treatment, such as an anti-viral prescription from a physician?"

C. Physiological biomarkers were measured for liver function, including $\mathrm{HBV}, \mathrm{HCV}$, and SGPT (normal range, $<40 \mathrm{mU} / \mathrm{mL}$ ) as measured by the collaborating hospital during the physical examination and serum hepatitis B surface antigen (HBsAg) and anti-HCV antibodies as determined using enzyme-linked immunoassays; fasting blood glucose (normal range, $<110 \mathrm{mg} / \mathrm{dL}$ ); systolic and diastolic blood pressure (normal range, $<140 / 90 \mathrm{mmHg}$ ); and body mass index (BMI), as calculated by weight $(\mathrm{kg})$ divided by the square of height $\left(\mathrm{m}^{2}\right)$. All standard references were from the Ministry of Health and Welfare [21].

\section{Procedure and ethical considerations}

This study was approved by the Ethical Committee of the Institutional Review Board (Chang Gung Memorial Hospital No 102-3331B). Written informed consent was obtained from all participants or their caregiver, after describing the study purpose and explaining that a free medical examination would be provided. A cover letter inviting participation in the study was sent to the 18 district public health nurses; this letter emphasized that the responses would remain confidential. Participants were allowed to ask questions and seek clarification about the study before they consented to participate. All participants were interviewed during a weekend in a school auditorium after the blood collection and physical examination by the staff of the collaborating hospital. To help build a caring environment, each participant was accompanied by a senior nursing student and community volunteer during the health screenings.

\section{Data analysis}

SPSS version 20 (IBM Corp., Armonk, NY) was used for data analyses. All tests were two-sided, and $p$ values $<0.05$ were considered statistically significant. The Chi-square statistic for testing the equality of proportions or rates was used to compare demographic variables, physiological biomarkers, and unhealthy behaviors between the individuals with or without HBV or $\mathrm{HCV}$ infection. Multivariate linear regression was used to analyze the factors associated with liver function that were chosen on the basis of relevant confounders after univariate analysis.

\section{Results}

\section{Demographic characteristics}

Of the 1024 disabled community residents who were eligible, 177 did not meet the inclusion criteria, resulting in 847 participants for data analyses. After excluding 1 participant who failed to complete the physical examination and 1 participant who had an incomplete questionnaire, the final data analyses were conducted with 845 participants. The mean age was 53.9 years $(\mathrm{SD}=18.4$; range 20-96), and the majority of the participants were men $(n=472,55.8 \%)$. Nearly one-third of the participants $(n=276,32.6 \%)$ had a physical disability, $27 \%(n=227)$ had an intellectual disability, and the remainder $(n=342$, $40.4 \%)$ had multiple disabilities. Nearly half (50.8 \%) did not have an education beyond middle school. More than two-thirds of the participants were unemployed $(n=609)$, $49 \%$ were married, and more than two-thirds (78.9\%) were living with their family, while the remainder lived with health care assistants or alone (Table 1).

The prevalence of $\mathrm{HBV}$ and $\mathrm{HCV}$ infections was $12.9 \%(n=109)$ and $14.1 \%(n=119)$, respectively (Table 1). Based on HBV infection, there were no statistically significant differences in gender, disability classification, education level, occupation status, and living arrangement; however, age and marital status were significantly different. Based on $\mathrm{HCV}$ infection, there were no significant differences in gender and living arrangement; however, the HCV carriers tended to be older $\left(\chi^{2}=24.6, p<0.001\right)$ and have a lower level of education $\left(\chi^{2}=16.4, p<0.001\right)$ than the non-carriers.

\section{Unhealthy behaviors between hepatitis B or C virus carriers}

Of the total sample, 77 (9.1\%) and 121 (14.3\%) participants were current users of alcohol and cigarette smokers, 
Table 1 Demographic characteristics of the samples $(N=845)$

\begin{tabular}{|c|c|c|c|c|}
\hline \multirow[t]{3}{*}{ Variables } & \multicolumn{2}{|c|}{ Hepatitis B infection } & \multicolumn{2}{|c|}{ Hepatitis C infection } \\
\hline & Negative & Positive & Negative & Positive \\
\hline & $N(\%)$ & & $N(\%)$ & \\
\hline Gender & $x^{2}=2.16$ & & $x^{2}=0.01$ & \\
\hline Female & $332(89.0)$ & $41(11.0)$ & $320(85.8)$ & $53(14.2)$ \\
\hline Male & $404(85.5)$ & $68(14.4)$ & $406(86.0)$ & $66(14.0)$ \\
\hline $\begin{array}{l}\text { Age (years) } \\
\text { Mean } \pm \text { SD }\end{array}$ & $51.5 \pm 14.7$ & $x^{2}=11.76^{* *}$ & $62.5 \pm 15.7$ & $x^{2}=24.63^{* * *}$ \\
\hline$\sim 39$ & $184(87.2)$ & $27(12.8)$ & $198(93.8)$ & $13(6.2)$ \\
\hline $40 \sim 64$ & $307(83.2)$ & $62(16.8)$ & $321(87.0)$ & $48(13.0)$ \\
\hline$\geq 65$ & $245(92.5)$ & $20(7.5)$ & $207(78.1)$ & $58(21.9)^{a}$ \\
\hline Disability classification & $x^{2}=1.21$ & & $x^{2}=7.16^{*}$ & \\
\hline Physical & $243(88.0)$ & $33(12.0)$ & $231(83.7)$ & $45(16.3)$ \\
\hline Intellectual & $193(85.0)$ & $34(15.0)$ & $207(91.2)$ & $20(8.8)$ \\
\hline Multiple disabilities & $300(87.7)$ & $42(12.3)$ & $288(84.2)$ & $54(15.8)$ \\
\hline Education & $x^{2}=0.84$ & & $x^{2}=16.36^{* * *}$ & \\
\hline$\leq$ Primary school & $378(88.1)$ & $51(11.9)$ & $348(81.1)$ & $81(18.9)$ \\
\hline$\geq$ Middle school & $356(86.0)$ & $58(14.0)$ & $376(90.8)$ & $38(9.2)$ \\
\hline Occupation & $x^{2}=0.11$ & & $x^{2}=5.09^{*}$ & \\
\hline With job & $207(87.7)$ & $29(12.3)$ & $213(90.3)$ & $23(9.7)$ \\
\hline Without job & $529(86.9)$ & $80(13.1)$ & $513(84.2)$ & $96(15.8)$ \\
\hline Marital status ${ }^{a}$ & $x^{2}=6.48^{*}$ & & $x^{2}=13.56^{* * *}$ & \\
\hline Single & $269(85.4)$ & $46(14.6)$ & $288(91.4)$ & $27(8.6)$ \\
\hline Married & $371(89.8)$ & $42(10.2)$ & $344(83.3)$ & $69(16.7)$ \\
\hline Others & $94(81.7)$ & $21(18.3)$ & $92(80.0)$ & $23(20.0)$ \\
\hline Living arrangement & $x^{2}=0.06$ & & $x^{2}=0.22$ & \\
\hline With families & $580(87.0)$ & $87(13.0)$ & $575(86.2)$ & $92(13.8)$ \\
\hline Other & 156 (87.6) & $22(12.4)$ & 151 (84.8) & 27 (15.2) \\
\hline
\end{tabular}

Pearson Chi-Square: ${ }^{*} p<0.05 ;{ }^{* *} p<0.01 ;{ }^{* * *} p<0.001$

${ }^{a}$ with missing data

respectively. More than half $(53.5 \%, n=452)$ reported irregular exercise, $66.7 \%(n=563)$ reported insufficient water intake, $81 \%(n=685)$ reported insufficient fruit intake, and $67.5 \%(n=570)$ reported insufficient vegetable intake. There were no significant differences between $\mathrm{HBV} / \mathrm{HCV}$ carriers and non-carriers in any of the healthrelated behaviors (Table 2). Regarding knowledge of hepatitis viral infection, the majority of $\mathrm{HBV} / \mathrm{HCV}$ carriers did not know the type of hepatitis infection and had not received adequate anti-viral treatment $(p<0.001$, Table 2$)$.

\section{Physiological biomarkers and health status among hepatitis carriers}

$\mathrm{HCV}$ carriers tended to have abnormal SGPT $\left(\chi^{2}=\right.$ 53.72, $p<0.001)$ and systolic blood pressure $\left(x^{2}=6.29\right.$, $p<0.05$ ) levels (Table 3). Considering the health status of the HBV and HCV carriers, 49.5 and $58.7 \%$ were overweight, respectively; 28.7 and $44.9 \%$ had abnormal
Table 2 Health-related behaviors among hepatitis B or C virus carriers

\begin{tabular}{|c|c|c|c|c|}
\hline \multirow[t]{3}{*}{ Variables } & \multicolumn{2}{|c|}{ Hepatitis B infection } & \multicolumn{2}{|c|}{ Hepatitis C infection } \\
\hline & Negative & Positive & Negative & Positive \\
\hline & \multicolumn{2}{|l|}{ N (\%) } & \multicolumn{2}{|l|}{ N (\%) } \\
\hline Alcohol use $\mathrm{u}^{\mathrm{a}}$ & $x^{2}=4.88$ & & $x^{2}=0.41$ & \\
\hline Never & $625(85.1)$ & $85(78.0)$ & $608(84.0)$ & $102(85.7)$ \\
\hline Current user & $61(8.3)$ & $16(14.7)$ & $68(9.4)$ & $9(7.6)$ \\
\hline Cessation & $48(6.5)$ & $8(7.3)$ & $48(6.6)$ & $8(6.7)$ \\
\hline Cigarette smoke & \multicolumn{2}{|l|}{$x^{2}=3.56$} & \multicolumn{2}{|l|}{$x^{2}=0.43$} \\
\hline Never & $555(75.4)$ & $75(68.8)$ & $544(74.9)$ & $86(72.3)$ \\
\hline Current smokers & 99 (13.5) & $22(20.2)$ & $103(14.2)$ & $18(15.1)$ \\
\hline Cessation & $82(11.1)$ & $12(11.0)$ & 79 (10.9) & $15(12.6)$ \\
\hline Adopting regular exercise ${ }^{a}$ & \multicolumn{2}{|l|}{$x^{2}=1.86$} & \multicolumn{2}{|l|}{$x^{2}=0.40$} \\
\hline Irregular & $387(52.7)$ & $65(59.6)$ & $392(54.0)$ & $60(50.8)$ \\
\hline Regular & $348(47.3)$ & $44(40.4)$ & $334(46.0)$ & $58(49.2)$ \\
\hline Water $(1500 \mathrm{~mL} / \text { day })^{\mathrm{a}}$ & \multicolumn{2}{|l|}{$x^{2}=0.21$} & \multicolumn{2}{|l|}{$x^{2}=0.26$} \\
\hline Sufficient & $245(33.4)$ & $34(31.2)$ & $242(33.5)$ & $37(31.1)$ \\
\hline Insufficient & $488(66.6)$ & $75(68.8)$ & $481(66.5)$ & $82(68.9)$ \\
\hline Fruit (2 servings/day) & \multicolumn{2}{|l|}{$x^{2}=0.01$} & \multicolumn{2}{|c|}{$x^{2}=0.77$} \\
\hline Sufficient & $139(18.9)$ & $21(19.3)$ & $134(18.5)$ & $26(21.8)$ \\
\hline Insufficient & $597(81.1)$ & $88(80.7)$ & $592(81.5)$ & $93(78.2)$ \\
\hline Vegetable (3 servings/day) & \multicolumn{2}{|l|}{$x^{2}=0.01$} & \multicolumn{2}{|l|}{$x^{2}=0.02$} \\
\hline Sufficient & $239(32.5)$ & $36(33.0)$ & 237 (32.6) & $38(31.9)$ \\
\hline Insufficient & $497(67.5)$ & $73(67.0)$ & $489(67.4)$ & $81(68.1)$ \\
\hline Awareness of viral infection & \multicolumn{2}{|l|}{$x^{2}=44.7^{* * *}$} & \multicolumn{2}{|c|}{$x^{2}=49.97^{* * *}$} \\
\hline Yes & $26(3.5)$ & $21(19.3)$ & $24(3.3)$ & $23(19.3)$ \\
\hline No & $710(96.5)$ & $88(80.7)$ & $702(96.7)$ & $96(80.7)$ \\
\hline Receiving antiviral treatment & \multicolumn{2}{|c|}{$x^{2}=21.31^{* * *}$} & \multicolumn{2}{|c|}{$x^{2}=30.56^{* * *}$} \\
\hline Yes & $12(1.6)$ & $10(9.2)$ & $10(1.4)$ & $12(10.1)$ \\
\hline No & 724 (98.4) & 99 (90.8) & 716 (98.6) & 107 (89.9) \\
\hline
\end{tabular}

***p $p<0.001$

a with missing data

systolic blood pressure, respectively; and 18.3 and $26.9 \%$ had high fasting blood glucose, respectively.

After adjusting for potential confounding variables, $\mathrm{HCV}$ infection $(\beta=0.2, p<0.001)$, HBV infection $(\beta=0.12$, $p=0.001)$, high fasting blood glucose levels $(\beta=0.11$, $p=0.001)$, overweight $(\beta=0.1, p=0.003)$, older age $(\beta=-0.08, p=0.027)$, and current alcohol drinking ( $\beta=0.08, p=0.028$ ) were significant in the regression analysis for elevated liver function (Table 4 ).

\section{Discussion}

Despite the limitations of the present study, including the convenience sampling that limits the generalizability of the findings to all adults with disabilities in Taiwan, four key findings regarding liver health in disabled adult 
Table 3 Physiological biomarkers associated with hepatitis B or C virus carriers

\begin{tabular}{|c|c|c|c|c|}
\hline \multirow[t]{3}{*}{ Variables } & \multicolumn{2}{|c|}{ Hepatitis B infection } & \multicolumn{2}{|c|}{ Hepatitis C infection } \\
\hline & Negative & Positive & Negative & Positive \\
\hline & \multicolumn{2}{|l|}{ N (\%) } & \multicolumn{2}{|l|}{ N (\%) } \\
\hline $\mathrm{SGPT}(\mathrm{mu} / \mathrm{mL})$ & $x^{2}=1.66$ & & $x^{2}=53.72^{* *}$ & \\
\hline$<40$ & $635(86.3)$ & $89(81.7)$ & $648(89.3)$ & $76(63.9)$ \\
\hline$\geq 40$ & $101(13.7)$ & $20(18.3)$ & $78(10.7)$ & $43(36.1)$ \\
\hline Body mass index $\left(\mathrm{kg} / \mathrm{m}^{2}\right)$ & $x^{2}=1.87$ & & $x^{2}=0.38$ & \\
\hline Average/under & $292(43.2)$ & $50(50.5)$ & $299(44.6)$ & $43(41.3)$ \\
\hline Overweight/Obesity & $384(56.8)$ & $49(49.5)$ & $372(55.4)$ & $61(58.7)$ \\
\hline SBP (mmHg) & $x^{2}=1.98$ & & $x^{2}=6.29^{*}$ & \\
\hline$<140$ & $470(64.4)$ & $77(71.3)$ & $482(66.9)$ & $65(55.1)$ \\
\hline$\geq 140$ & $260(35.6)$ & $31(28.7)$ & $238(33.1)$ & $53(44.9)$ \\
\hline $\mathrm{DBP}(\mathrm{mmHg})$ & $x^{2}=0.54$ & & $x^{2}=0.03$ & \\
\hline$<90$ & $558(76.4)$ & $86(79.6)$ & $554(76.9)$ & $90(76.3)$ \\
\hline$\geq 90$ & $172(23.6)$ & $22(20.4)$ & $166(23.1)$ & $28(23.7)$ \\
\hline $\mathrm{FBG}(\mathrm{mg} / \mathrm{dL})$ & $x^{2}=0.66$ & & $x^{2}=2.56$ & \\
\hline$<109$ & $575(78.2)$ & $89(81.7)$ & 577 (79.6) & $87(73.1)$ \\
\hline$\geq 110$ & $160(21.8)$ & $20(18.3)$ & $148(20.4)$ & $32(26.9)$ \\
\hline
\end{tabular}

Abbreviations: SGPT serum glutamic pyruvic transaminase, SBP systolic blood pressure, $D B P$ diastolic blood pressure, $F B G$ fasting blood glucose $p<0.05 ;{ }^{* * *} p<0.001$

$\mathrm{HBV}$ or $\mathrm{HCV}$ carriers emerged from this study. First, there was a high prevalence of $\mathrm{HCV}$ infection in adults with disabilities, especially in older people and those with a low socioeconomic status. Second, few people are aware of viral infections, and very few receive antiviral treatment, which are effective and can successfully cure the infection. Third, most of the disabled participants with or without hepatitis reported some specific unhealthy behaviors. Fourth, high fasting blood glucose levels, overweight, and alcohol consumption were important and preventable risk factors, in addition to $\mathrm{HBV} / \mathrm{HCV}$ infection and older age.

The prevalence rate of $\mathrm{HBV}$ in the present study (12.9\%) was lower than the nationwide prevalence (15-20\%), but higher than those of the adult population in different geographical areas, including subSaharan Africa and East Asia (5-10 \%), the Middle East (2-5 \%), and Western Europe and North America (1\%) [1-4]. Therefore, although the number of newly acquired HBV infections in Taiwan has declined substantially since the implementation of the national immunization program, the prevalence of chronic HBV and HCV infections remains high in some rural areas $[3,10,12]$, including the western coastal areas (HBV, 18.7 \%; HCV, $20.8 \%$ ) [10].

Based on the results of the present study (Table 2), possible reasons for higher rates of $\mathrm{HCV}$ infection in adults with disabilities living in rural areas (14.1\%) than the nationwide prevalence (2-3\%) include health disparity resulting from the limited resources and unqualified medical personnel using unsterilized materials [4], lack of education, poverty, illiteracy, and lack of information about virus-related hepatitis. Although there is currently no vaccine for $\mathrm{HCV}$, evidence strongly suggests that some antiviral drugs are effective for eradicating the entire virus and reducing the incidences of hepatic cancer by $78 \%$ and liver cirrhosis by $47 \%$ [1-4]. Fortunately, antiviral treatments, such as interferon, lamivudine, adefovir, and ribavirin are covered by the Taiwan national health insurance [4]. Therefore, strategies to enhance the awareness of virus infection and motivate disabled residents to receive and complete the entire course of antiviral treatments are important issues for clinicians and primary health care providers.

The present study also revealed that many disabled participants have unhealthy behaviors, such as inadequate exercise and insufficient water, fruit, and vegetable intake.

Table 4 Factors associated with elevated liver function (SGPT)

\begin{tabular}{|c|c|c|c|c|c|c|}
\hline \multirow[t]{2}{*}{ Variables } & \multicolumn{2}{|c|}{ Unstandardized } & \multirow[t]{2}{*}{ Beta } & \multirow[t]{2}{*}{ t value } & \multirow[t]{2}{*}{$p$} & \multirow[t]{2}{*}{$95 \% \mathrm{Cl}^{\mathrm{a}}$} \\
\hline & B & SE & & & & \\
\hline Constant & 19.85 & 1.67 & & 11.89 & $<0.001$ & $16.58 \sim 23.13$ \\
\hline HCV (1 = positive) & 15.28 & 2.59 & 0.20 & 5.90 & $<0.001$ & $10.19 \sim 20.37$ \\
\hline HBV (1 = positive) & 9.30 & 2.68 & 0.12 & 3.47 & 0.001 & $4.04 \sim 14.56$ \\
\hline $\begin{array}{l}\text { Fasting blood glucose } \\
(1>110 \mathrm{mg})\end{array}$ & 7.26 & 2.24 & 0.11 & 3.25 & 0.001 & $2.87 \sim 11.65$ \\
\hline BMI (1 = overweight/obesity) & 5.71 & 1.89 & 0.10 & 3.02 & 0.003 & $2.00 \sim 9.42$ \\
\hline Age $(1>65)$ & -4.40 & 1.98 & -0.08 & -2.22 & 0.027 & $-8.29 \sim-0.51$ \\
\hline Alcohol (1 = current drinker) & 6.15 & 2.78 & 0.08 & 2.21 & 0.028 & $0.68 \sim 11.61$ \\
\hline Smoking (1 = current smoker) & 1.91 & 2.35 & 0.03 & 0.81 & 0.418 & $-2.71 \sim 6.53$ \\
\hline
\end{tabular}

Abbreviations: SGPT serum glutamic pyruvic transaminase, $H C V$ hepatitis $C$ virus, $B M I$ body mass index, $H B V$ hepatitis $B$ virus

${ }^{a} \mathrm{Cl}$ : confidence interval

Dependent variable: SGPT

Model summary: $F=11.92, p<0.001$ 
Moreover, 9.1 and $6.6 \%$ of the participants reported current and previous alcohol consumption, respectively (Table 2). Although these habits were not directly correlated with health status, previous studies have reported that insufficient exercise, and inadequate water, fruit, and vegetable intake were significantly associated with obesity/ overweight and HCC [20-23]. Furthermore, poor adherence to a Mediterranean diet was particularly detrimental for the risk of HCC in chronically infected HBV and/or HCV carriers [22, 23].

The modifiable factors significantly associated with elevated liver function included high fasting blood glucose levels, overweight, and alcohol drinking in the final regression model, in addition to $\mathrm{HBV} / \mathrm{HCV}$ infection. Similarly, a previous study indicated that important lifestyle factors, such as alcohol consumption, diabetes, and obesity, also contribute to HCC [20], and increasing evidence is emerging that obesity is a major etiology for abnormal liver function among the young generation [24]. A meta-analysis of cohort studies reported a 17 and $90 \%$ increased risk of HCC for overweight and obese people, respectively, compared with those of normal weight [25]. The association between obesity and non-alcoholic fatty liver disease could explain this increased risk [22-24]. In addition, HBV or HCV carriers in an Aboriginal population with a high incidence of alcohol consumption and smoking also had the most elevated levels of biomarkers of abnormal liver function [26].

Considering the limitations associated with physical, mental, or multiple disabilities among this vulnerable population, the inclusion of healthy lifestyle modifications for people with disabilities living in rural areas is an important strategy for primary health care providers. In addition, more convenient $\mathrm{HBV}$ vaccine booster programs could be provided for disabled young people whose HBV antibodies are no longer present following the 3 vaccination doses in infancy. Furthermore, access to antiviral treatments at 6-12-month periods for $\mathrm{HCV}$ carriers with disabilities is an important strategy for health care providers and district governments. Moreover, further studies are necessary to explore and initiate potential health promotion programs that encourage regular monitoring (e.g., every 3-6 months) for the early diagnosis of chronic liver disease, adoption of appropriate therapies, and avoiding overuse of alcohol and smoking for community-dwelling adults with disabilities.

\section{Limitations}

This study had certain limitations. First, the participants were not randomly recruited and were from the same geographic area, Chiayi County, which limits the generalizability of these findings. Second, the descriptive study design does not allow for causality to be established, and possible confounders might not have been measured. Third, self-reporting often results in underestimation of unhealthy behaviors, such as the amount and type of alcohol consumed and extent of cigarette smoking. Finally, selection and recall bias need to be considered because of the various health conditions of the participants.

\section{Conclusions and implications}

There was a high prevalence of $\mathrm{HCV}$ infection among adults with disabilities in the present study; few of the participants possessed an awareness of their liver health, and very few received early treatment or information on the prevention of liver cancer. Despite the presence of some unmodifiable risk factors, early detection of unhealthy behaviors and referral for further diagnosis of $\mathrm{HBV} / \mathrm{HCV}$ carriers, increasing awareness of virus-related hepatitis and its consequences, providing accessible HBV vaccine booster programs and antiviral treatments for $\mathrm{HCV}$ carriers, and initiating health promotion programs are important health strategies for these minority adults.

\section{Competing interest}

The authors declare that they have no competing interests.

\section{Authors' contributions}

MYC, SWJ, and MSL were involved with the conceptualization of the study, study design, data analysis, and editing of the final draft for publication. WNC, LJL, and PHC participated in the conceptualization of the study and data collection. All authors read and approved the final manuscript.

\section{Acknowledgments}

The authors would like to thank the individuals who participated in this study for their support in making this study possible. We would like to acknowledge the staff of the Chiayi County Health Bureau, Buddhist-Tzu Chi Hospital, and Public Health Nurses for providing administrative support.

\section{Author details}

${ }^{1}$ Nursing Department, Chang Gung University of Science and Technology, Taoyuan, Taiwan. ${ }^{2}$ Deparment of Internal Medicine, Chang Gung Memorial Hospital, Yunlin, Taiwan. ${ }^{3}$ Department of Ophthalmology, Chang Gung Memorial Hospital, Chiayi, Taiwan. ${ }^{4}$ Department of Orthopedic Surgery, Chang Gung Memorial Hospital, Yunlin, Taiwan. ${ }^{5}$ College of Nursing, Chang Gung University of Science and Technology, No. 2, Chiapu Rd. West Sec., Putz City, Chiayi County 61363, Taiwan.

Received: 5 September 2015 Accepted: 8 February 2016

Published online: 13 February 2016

\section{References}

1. World Health Organization. Hepatitis C. Available from: [http://www.who.int/ mediacentre/factsheets/fs164_apr2014/en/]. Access date of Dec 25, 2015.

2. World Health Organization. Hepatitis B. Available from: [http://www.who.int/ mediacentre/factsheets/fs204/en/]. Access date of Dec 25, 2015.

3. Centers for Disease Control (CDC), Taiwan. Acute hepatitis B virus infection 2015. Available from: [http://www.cdc.gov.tw/home/Hepatitis_B_Acute]. Access date of Dec 25, 2015.

4. Centers for Disease Control (CDC), Taiwan. Acute hepatitis C virus infection. Available from: [http://www.cdc.gov.tw/home/Hepatitis_C_Acute]. Access date of Dec 25, 2015.

5. World Health Organization. Prevent hepatitis. Available from: [http://www. who.int/campaigns/hepatitis-day/2015]. Access date of Dec 25, 2015.

6. Ministry of Health and Welfare. Cause of death statistics. Available from: [http://www.mohw.gov.tw/cht/DOS/Statistic.aspx?f_list_no=312\&fod_list_ no=1601]. Access date of Dec 25, 2015. 
7. Health Promotion Administration (HPA), Ministry of Health and Welfare. Liver diseases 2015. Available from: [http://www.hpa.gov.tw/Bhpnet/Web/ HealthTopic/TopicArticle.aspx? $\mathrm{No}=201511110003 \&$ parentid=201511110001]. Access date of Dec 25, 2015.

8. Chang $\mathrm{MH}$. Cancer prevention by vaccination against hepatitis B. Recent Results Cancer Res. 2009;181:85-94.

9. Lin CC, Yang CY, Shih CT, Chen BH, Huang YL. Waning immunity and booster responses in nursing and medical technology students who had received plasma-derived or recombinant hepatitis $B$ vaccine during infancy. Am J Infect Control. 2011;39:408-14.

10. Fan JY, Huang TJ, Jane SW, Chen MY. Prevention of liver cancer through the early detection of risk-related behavior among hepatitis B or C carriers. Cancer Nurs. 2015;38:169-76.

11. Lu SN, Chen CH, Chen TM, Lee PL, Wang JH, Tung HD, et al. Hepatitis B virus infection in adolescents in a rural township -15 years subsequent to mass hepatitis B vaccination in Taiwan. Vaccine. 2006;24:759-65.

12. Lu SN, Su WW, Yang SS, Chang TT, Cheng KS, Wu JC, et al. Secular trends and geographic variations of hepatitis B virus and hepatitis $C$ virus-associated hepatocellular carcinoma in Taiwan. Int J Cancer. 2006;119:1946-52.

13. Ministry of the Interior (MOI), Taiwan, ROC. Report on physically and mentally disabled citizens living and demand assessment survey. Available from [http://www.mohw.gov.tw/EN/Ministry/Statistic.aspx?f_list_no=474]. Access date of Dec 25, 2015.

14. World Health Organization. Disability. Available from [http://www.who.int/ topics/disabilities/en/] Access date of Dec 25, 2015.

15. Gidding HF, Dore GJ, Amin J, Law MG. Trends in all cause and liver-related hospitalizations in people with hepatitis B or C: A population-based linkage study. BMC Public Health. 2011;11:52.

16. Jee SH, Ohrr H, Sull JW, Samet JM. Cigarette smoking, alcohol drinking, hepatitis B, and risk for hepatocellular carcinoma in Korea. J Natl Cancer Inst. 2004:96:1851-56

17. Su FH, Chen JD, Cheng SH, Sung KY, Jeng JJ, Chu FY. Waning-off effect of serum hepatitis B surface antibody amongst Taiwanese university students: 18 years post-implementation of Taiwan's national hepatitis B vaccination program. J Viral Hepat. 2008:15:14-9.

18. Wang LY, You SL, Lu SN, Ho HC, Wu MH, Sun CA, et al. Risk of hepatocellular carcinoma and habits of alcohol drinking, betel quid chewing and cigarette smoking: A cohort of $2416 \mathrm{HBsAg}$-seropositive and $9421 \mathrm{HBsAg}$-seronegative male residents in Taiwan. Cancer Causes Control. 2003;14:241-50.

19. Robertson J, Emerson E, Baines S, Hatton C. Obesity and health behaviors of British adults with self-reported intellectual impairments: cross sectional survey. BMC Public Health. 2014;14:219.

20. Scientific report of the 2015 Dietary Guidelines Advisory Committee. Part D, Chapter 1. Food and nutrient intakes and health: current status and trends. Page 28, lines 1024-1025 and 1053-1055. Available from [http://www.health. gov/dietaryguidelines/2015-scientific-report/pdfs/scientific-report-of-the-2015dietary-guidelines-advisory-committee.pdf]. Access date of Dec 25, 2015.

21. Health Promotion Administration, Ministry of Health and Welfare. Metabolic syndrome. http://www.hpa.gov.tw/BHPNet/Web/HealthTopic/ TopicArticle.aspx? $\mathrm{No}=200712250123 \&$ parentid $=200712250023$ Access date of Dec 25, 2015.

22. Montella M, Crispo A, Giudice A. HCC, diet and metabolic factors: Diet and HCC. Hepat Mon. 2011;11:159-62.

23. Turati F, Trichopoulos D, Polesel J, Bravi F, Rossi M, Talamini R, et al. Mediterranean diet and hepatocellular carcinoma. J Hepatol. 2014;60:606-11.

24. Kao JT, Wang JH, Hung CH, Hu TH, Lee CM, Hung SF, et al. Changing etiology of liver dysfunction in the new generation of a hepatitis $\mathrm{B}$ and $\mathrm{C}$ endemic area: cross-sectional studies on adolescents born in the first 10 years after universal hepatitis B vaccination. Liver Int. 2008:28:1298-04.

25. Blonski W, Kotlyar DS, Forde KA. Non-viral causes of hepatocellular carcinoma. World J Gastroenterol. 2010;16:3603-15.

26. Lin CF, Shiau TJ, Ko YC, Chen PH, Wang JD. Prevalence and determinants of biochemical dysfunction of the liver in Atayal aboriginal community of Taiwan: Is betel nut chewing a risk factor? BMC Gastroenterol. 2008;8:13.

\section{Submit your next manuscript to BioMed Central and we will help you at every step:}

- We accept pre-submission inquiries

- Our selector tool helps you to find the most relevant journal

- We provide round the clock customer support

- Convenient online submission

- Thorough peer review

- Inclusion in PubMed and all major indexing services

- Maximum visibility for your research

Submit your manuscript at www.biomedcentral.com/submit
) Biomed Central 